\title{
IMPLANTAÇÃO DO SISTEMA DE DISTRIBUIÇÃO POR DOSE UNITÁRIA DE MEDICAMENTOS INJETÁVEIS
}

\section{INTRODUÇÃO}

A Dose Unitária (DU) é um sistema de distribuição de medicamentos, em dosagens prontas para serem administradas, garantindo maior segurança ao paciente.

\section{OBJETIVO}

Implantar o sistema de distribuição de medicamentos injetáveis por DU.

\section{METODOLOGIA}

A Central de Dose Unitária (CDU) dispõe de 108 m2 de área física, contendo área limpa com duas salas de manipulação de medicamentos: injetáveis e antineoplásicos. A CDU iniciou suas atividades com a manipulação de antineoplásicos e posteriormente realizou um projeto de expansão, disponibilizando DU dos medicamentos injetáveis utilizados para os pacientes internados. Farmacêuticos foram contratados para contemplar Assistência Farmacêutica por 24 horas. Um programa para acompanhar as prescrições médicas foi desenvolvido. Elaborouse uma tabela de padronização de diluição dos medicamentos. Estabeleceu-se o processo de forma a garantir segurança e diversas checagens: prescrição médica eletrônica, aprazamento eletrônico pelo enfermeiro, avaliação da prescrição pelo farmacêutico, confecção de etiquetas de identificação, manipulação das DU exclusivamente pelo farmacêutico, entrega por horário de administração, conferência da DU com a prescrição médica no recebimento e antes da administração.

\section{RESULTADOS}

O número de DU disponibilizada foi 46.967 em 2016; 123.825 em 2017 e 126.272 em 2018. O índice de reaproveitamento foi de $18 \%$ em 2016, 40\% em 2017 e 57\% em 2018.
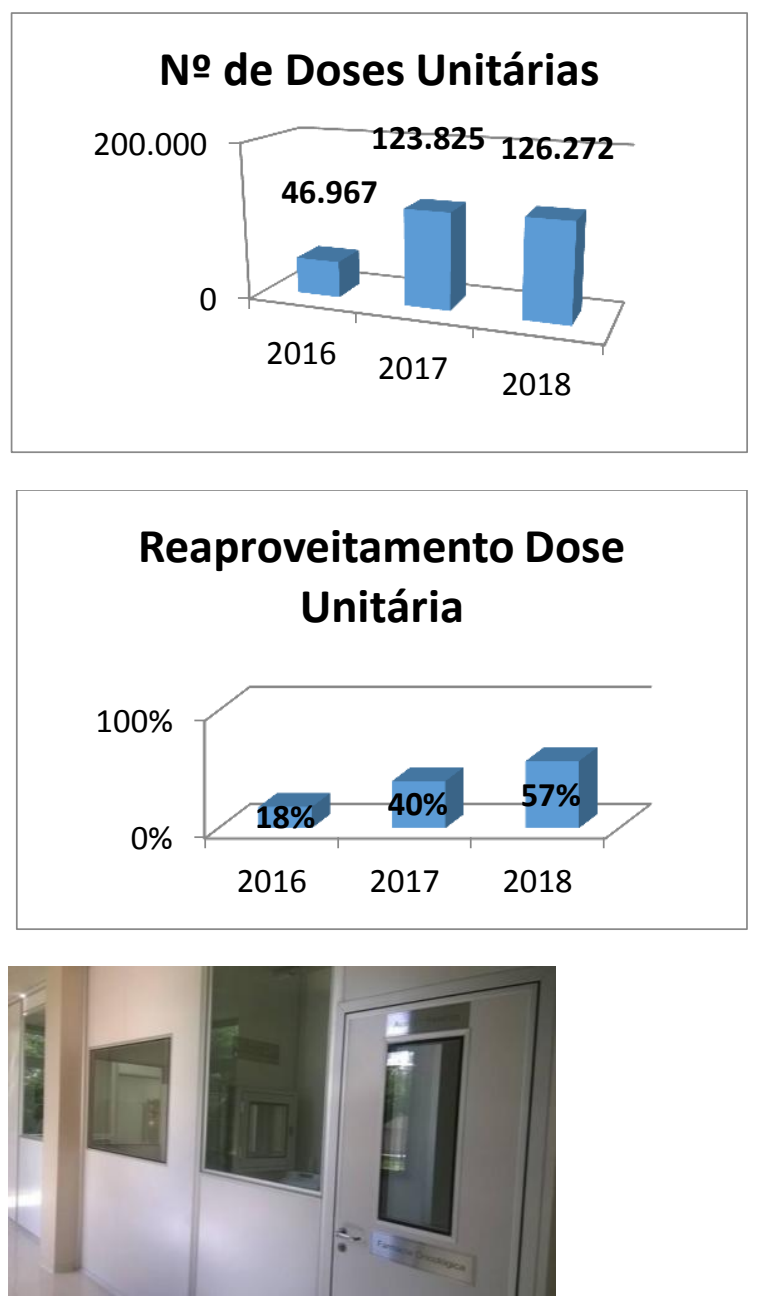

\section{CONCLUSÃO}

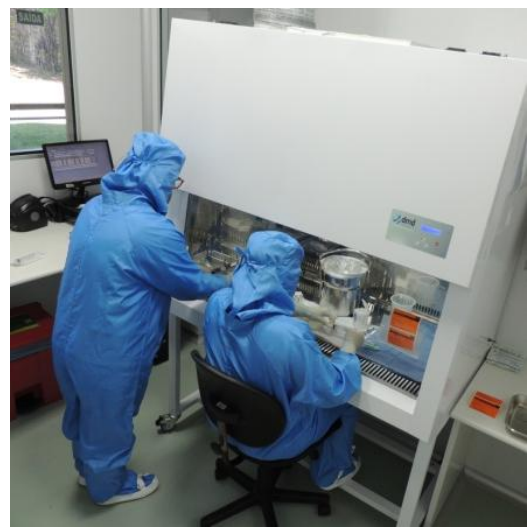

Esta ação interdisciplinar tem proporcionado avaliação farmacêutica das prescrições, preparo dos medicamentos em ambiente adequado, padronização e rastreabilidade do processo, checagens em diversos pontos no processo, aumento da disponibilidade da equipe de enfermagem para assistência ao paciente, redução de eventos adversos relacionados aos medicamentos, redução do desperdício com os medicamentos e economia para instituição. 